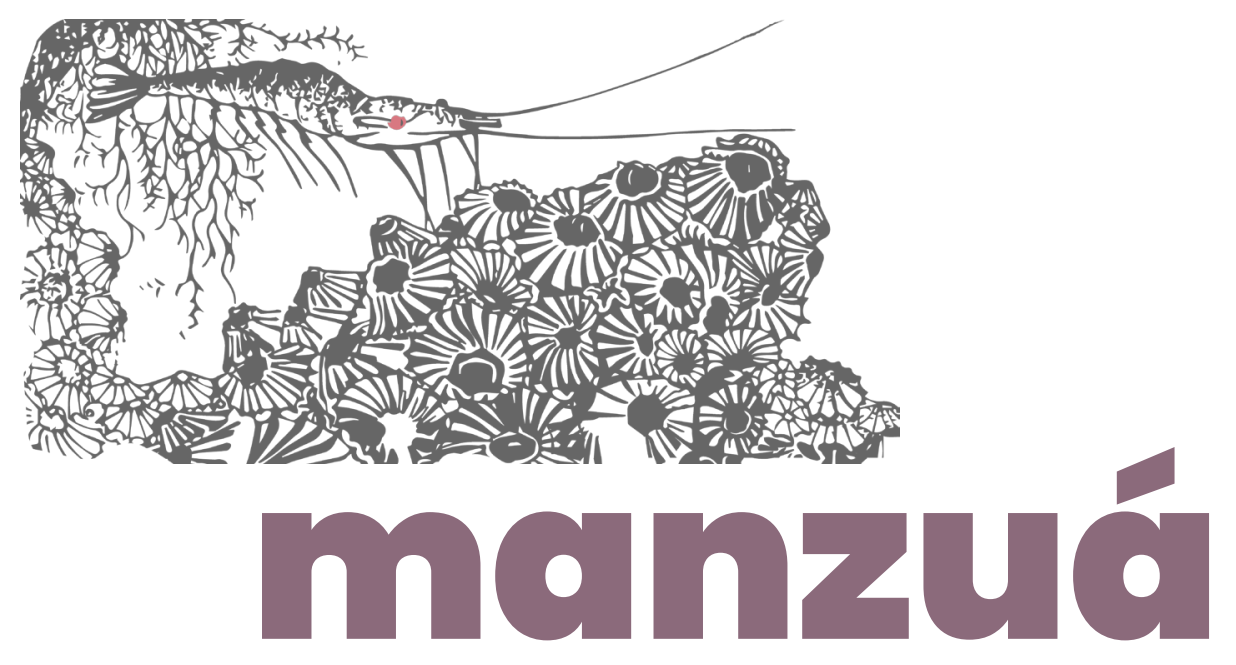

\title{
CIRCUNSCREVENDO AS PEQUENAS PERFORMANCES PARA ISOLADOS Artigo Thaise Nardim?
}

\section{RESUMO}

O texto apresenta a ação em arte, educação e pesquisa intitulada "Pequenas Performances Para Isolados - arte do bem para mundos possíveis", proposição mediada exclusivamente pelo aplicativo de mensagens instantâneas WhatsApp. Após enunciar a localização epistêmica da autora e introduzir a noção de pesquisa-docênciacriação, o texto busca circunscrever a proposta, observando, então, temática que ela incorpora. Por fim, retoma a relação entre a ação e a noção de pesquisa-docência-criação, apontando para a necessidade da materialização de orientações metodológicas em práticas.

Palavras-chave: aprendizagem mediada por tecnologias; arte de instruções; arte da performance; ensino de arte; pesquisa em arte.

1 - Professora de Arte da Performance na Universidade Federal do Tocantins (Licenciatura em Artes - Teatro). Doutoranda em Artes da Cena pela Universidade Estadual de Campinas. Membro do Grupo de Pesquisa Arte na Pedagogia, integrado ao Diretório de Grupos de Pesquisa do CNPq. 


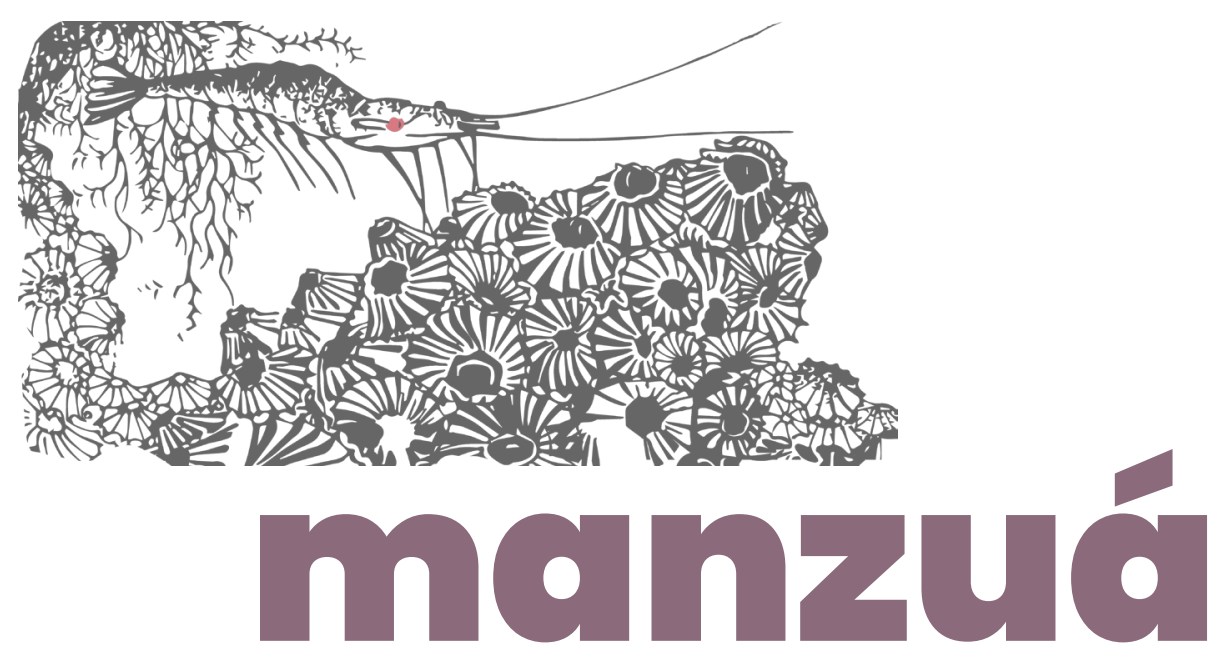

\section{ABSTRACT}

This paper presents an action in art, education and research entitled "Pequenas Performances para Isolados - arte do bem para mundos possiveis", mediated exclusively by the instant messaging application WhatsApp. After stating the author's epistemic location and introducing the notion of research-teaching-creation, the text seeks to circumscribe the proposal, observing, then, the theme that it incorporates. Finally, it resumes the relationship between that action and the notion of research-teaching-creation, pointing to the need to materialize methodological guidelines in practices.

Keywords: arts based research; art teaching; instructional art; performance art; technology mediated learning; 


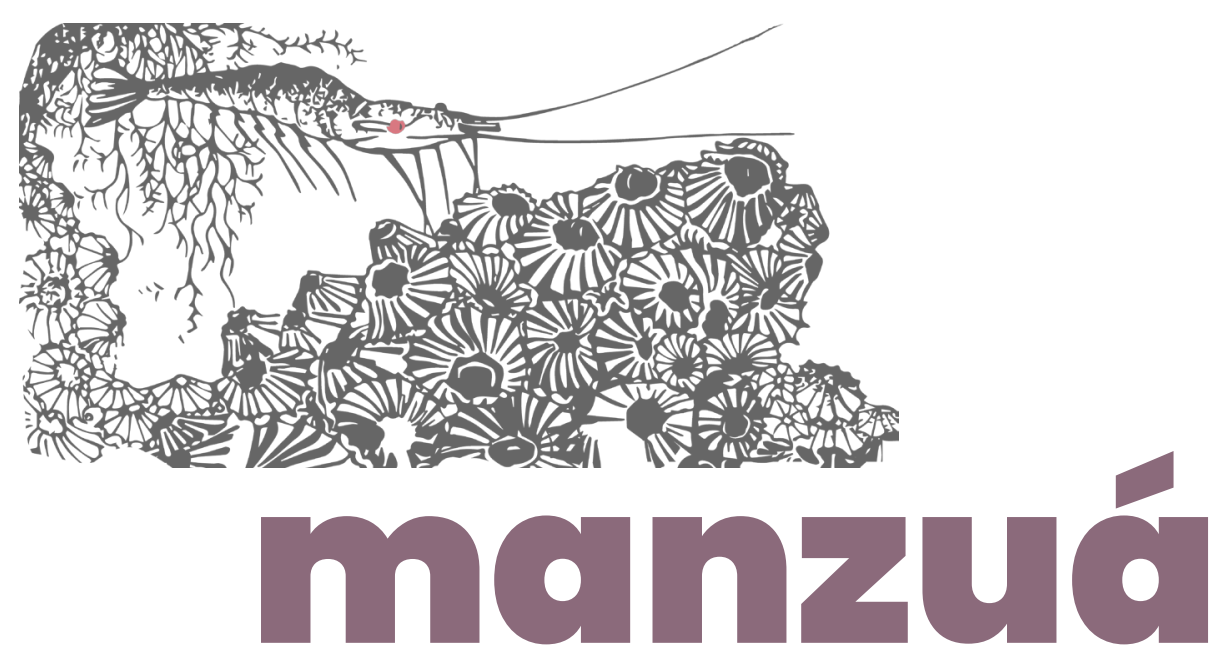

\section{INTRODUZINDO}

Inicio esta escrita tendo como disparador um convite para abordar as "Pequenas Performances Para Isolados - arte do bem para mundos possiveis", ação que mescla arte, educação e pesquisa que venho desenvolvendo junto a muitas outras pessoas participantes desde maio deste ano de 2020 , período durante o qual me encontro em isolamento social preventivo à COVID-19.

Tendo já escrito alguns textos em torno de minha experiência com a ação - textos não publicados até o momento em que escrevo este -, aquiesço agora ao impulso que me orienta a tratar da estruturação da proposição dessas Pequenas Performances. Acolho o impulso artístico-acadêmico de colocar-me no movimento de ir e vir entre circunscrevê-la (à estrutura) e pontuar algumas impressões que sua elaboração e vivência imprimiu em minha percepção de proponente, o que implica falar sobretudo a partir de uma orientação que eu usualmente tendo a entender como perigosa, a saber, aquela da intencionalidade.

Ensaiar em texto a narrativa de uma proposição que combina (fusiona, amalgama, mescla) a criação artística, a pesquisa e a docência não é uma experiência inédita para mim. Contudo, tenho a tendência de evadir-me da tentação de escrever sobre as intenções que eu tinha - ou que hoje acredito que tinha - quando da elaboração de um trabalho. Mas, como afirmei, parece-me agora que chega $o$ momento de abordar os rastros de pensamento - aqueles que se fizerem visiveis - sobre os quais as Pequenas Performances firmam seus múltiplos pés - sem reconhecer o produto como ponto final, mas sim como pouso ou pausa; contornando e/ou não dissimulando intenções interpretativas, mas posicionando-se e enunciando minha localização; e buscando no trajeto do narrar elementos para pensar, 


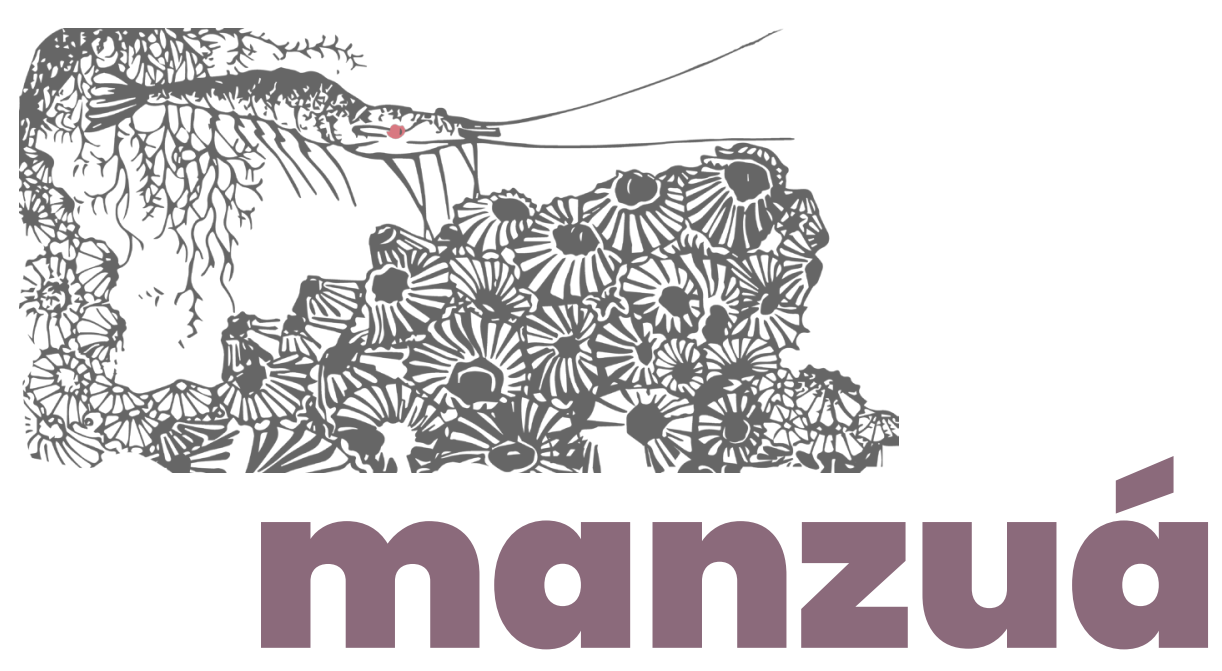

uma vez mais, como eu, Thaíse, posso vir a assumir consistência (EUGENIO, 2019) em pesquisa-docência-criação (NARDIM, 2020a).

Pesquisa-docência-criação vem sendo, em meu trabalho dos últimos anos, aquilo que costumamos entender como uma metodologia - ou, como preferiria Donna Haraway, vem sendo meus "modos definidos de trabalhar que se tornaram mais conscientes com o passar dos anos (2015, p. 51)" - sendo eu não tão experiente e, daí deriva, menos consciente que ela. A definição dos modos, em meu caso, mais que um procedimento descritivel é um modo operativo ou a tentativa de habitá-lo - o incessante e suave e esforçado e insistente e amoroso trabalho de permanecer habitando o modo operativo "AND" (EUGENIO, 2019).

Para a finalidade desta apresentação, sem pretender estenderme e ainda menos esgotar o tema, posso dizer que o Modo Operativo AND é como se frequenta um âmbito de característica intervalar âmbito que, neste pensamento, é chamado de " $E$ " -, composto por faixas de frequência que atravessam as linhas que desenham os encontros e faz emergir vida para além e aquém de prescrições, regras, normas (EUGENIO, 2019). "E" é o âmbito dos acidentes que irrompem como irrompem a todo instante em toda a vida, e diverge dos regimes sensíveis do "É" - reinado do dogma e da identidade e do "OU" - primado da indiferença e do tudo-pode/tanto-faz, ao tempo em que também não consiste na mais pura aceleração que, de tamanha, poderia fazer-se desintegração. Modo Operativo AND é aquilo para que treino a atenção, pois é com o perceber afiado, afinado e sintonizado em E que poderei apenas parar e reparar - no caso deste texto, reparar naquilo que reúno enquanto memória de minhas intenções quando da composição das "Pequenas Performances Para Isolados" - sem arriscar-me a indesejáveis permanências. 


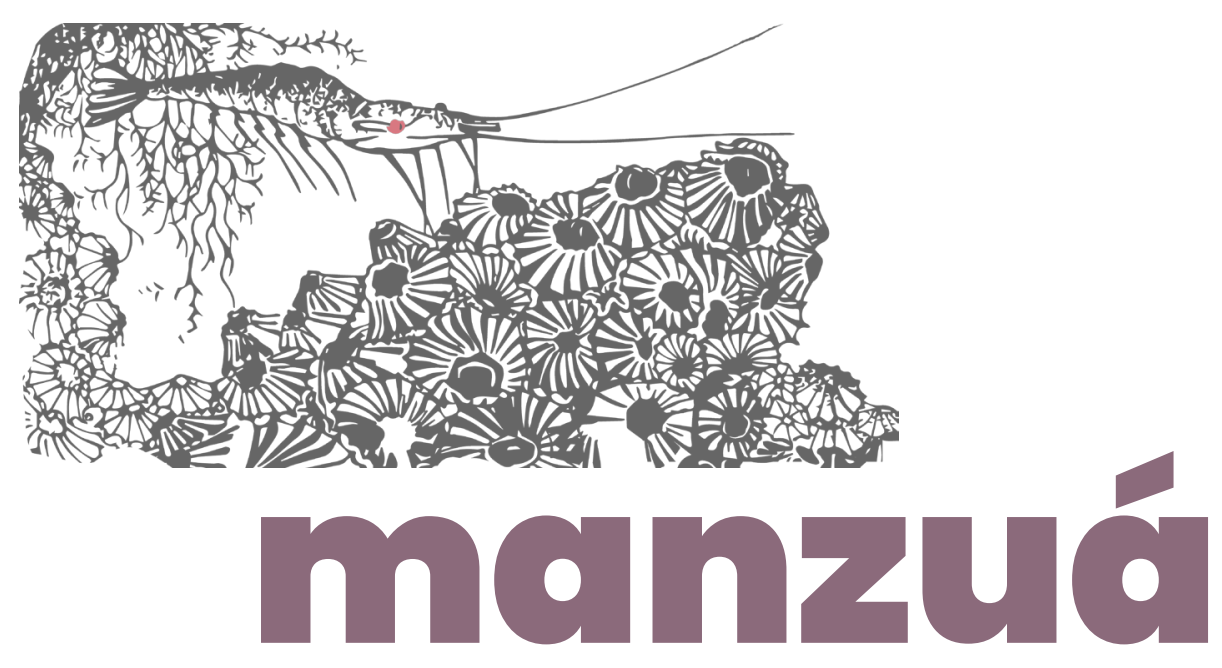

A pesquisa-docência-criação é a forma-conteúdo por meio da qual coloco o Modo Operativo AND para rodar - elejo o verbo para aproximar a pessoa leitora da imagem de um sistema operacional - nas contingências em que estou imersa e que comigo emergem: um corpo nascido e identificado como de mulher, hoje com 36 anos; o trabalho como professora universitária há dez anos, no curso de Licenciatura em Teatro da Universidade Federal do Tocantins, a dois mil quilômetros de minha cidade de origem e de minha família; a insistência na criação praticada enquanto artista da performance e (co-)inventora de espaços-tempos para compartilhar performances; os desejos transartísticos e transdisciplinares, desejo de artes visuais e de teatro e de música e de dança e de tudo que está entre eles e que a partir deles se derrama, e de filosofia e de antropologia e de literatura e de pedagogia (e de ensino e de aprendizagem) e de universidade - por que não?

Pesquisa-docência-criação é a forma tática e esteticamente pouco agradável que escolhi para nomear a prática de ser artista enquanto docente, docente enquanto pesquisadora, pesquisadora enquanto artista e tudo isso ao mesmo tempo - por vezes uma das funções assumindo mais relevo que as demais, logo depois esse relevo se dissolvendo e criando brecha para a relevância de outro dos âmbitos - mas sempre na dança entre instâncias dessa unidade que é múltipla.

"Pequenas Performances Para Isolados" é a materialização de pesquisa-docência-criação operando como insistência em modo AND e, tendo em vista que a pessoa leitora poderá encontrarse diretamente com essa sua concretude, interrompo agora as descrições sobre essa minha prática "metodológica". 


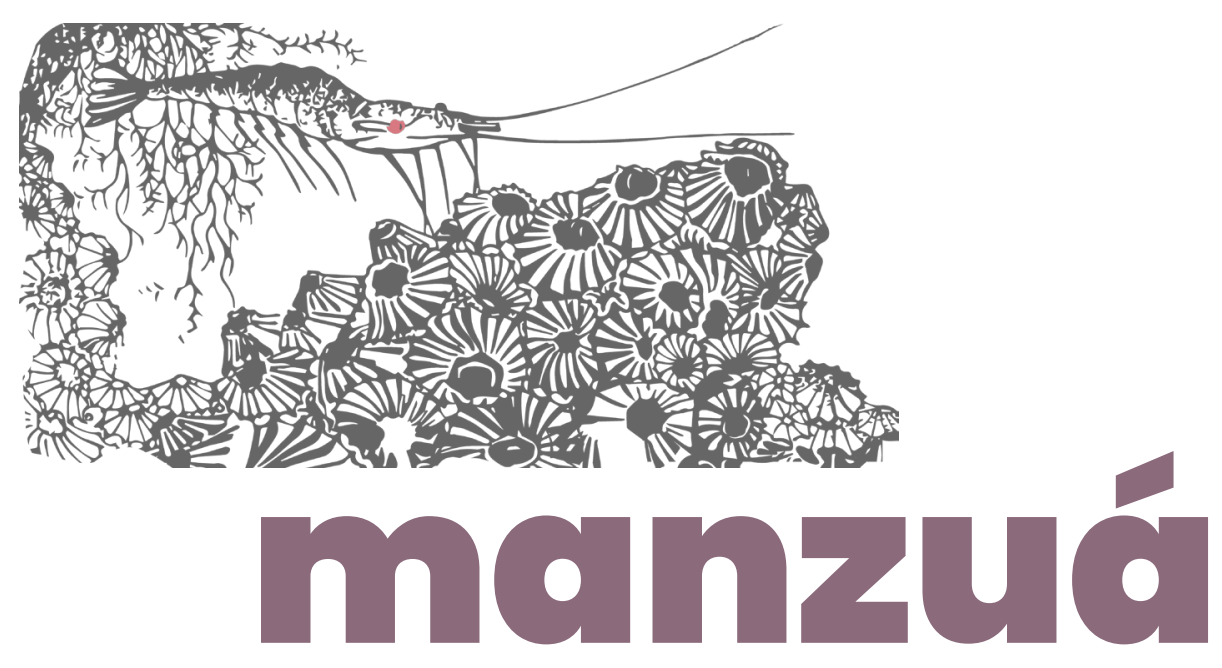

\section{CIRCUNSCREVENDO}

"Pequenas Performances Para Isolados - arte do bem para mundos possíveis" assumiu sua forma integral em três ocasiões - que escolherei, daqui em diante, nomear como ofertas: a primeira delas durante trinta dias entre os meses de maio e junho; a segunda delas, com a mesma duração, entre julho e agosto; e, por fim, a terceira, entre agosto e setembro. A primeira oferta foi realizada como um curso de extensão promovido pela Universidade Federal EXCLUÍDO PARA MANUTENÇÃO DE ANONIMATO, instituição em que leciono; a segunda e a terceira ofertas foram incorporadas à programação da unidade Avenida Paulista do SESC São Paulo, por intermédio da programadora Laís de Jesus, que participou da primeira oferta.

A proposta consiste numa realização dura 30 dias, além de algum tempo prévio a eles, necessário à divulgação e às inscrições. Divulgação realizada, pessoas inscritas, todas são comunicadas de que receberão um e-mail no dia anterior àquele previsto para o início, em sentido estrito, da ação. Esse e-mail, enviado a partir do meu endereço eletrônico pessoal, contém as informações necessárias para que a pessoa participante possa aderir aos grupos de WhatsApp por meio do qual a ação será realizada; após essa comunicação inicial, tudo o que acontecer na ação se dará única e exclusivamente por meio de WhatsApp - e a pessoa participante é então informada disso. É informada também de algumas recomendações técnicas que anunciam por exemplo, a possibilidade de desabilitar as notificações do aplicativo ou o download automático de mídia - informações relevantes para evitar constrangimentos no cotidiano, já que serão trocadas muitas mensagens no decorrer dos dias e muitas delas conterão fotografias, o que pode levar a uma sobrecarga da memória de certos dispositivos. Além disso, o e-mail sugere alguns modos de 


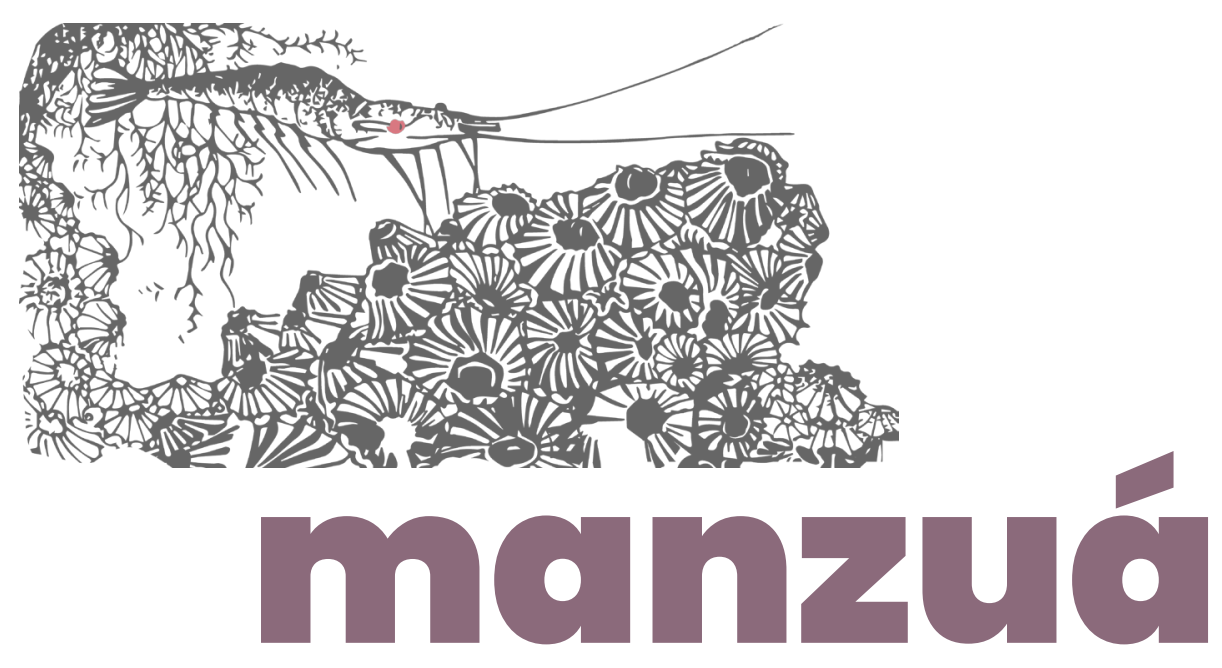

proceder que se alinham com o conceito e com o ambiente afetivo que intencionei para o trabalho - como, por exemplo, uma orientação para que em todas as interações as pessoas participantes busquem cuidar de si, cuidar dos outros, cuidar de seu processo criativo e cuidar do coletivo que então compomos.

Pelo seu teor e a função que viria a assumir no processo, a redação dessa mensagem inicial demandou de mim um trabalho de apuro tanto técnico quanto poético. Afinal, para além de informações objetivas de cuja precisão a ação dependia para acontecer na forma disparadora que eu havia elaborado, as orientações do campo afetivo cobravam rigor a cada palavra empregada, propiciando-me a sensação de estar compondo um misto de poema e texto acadêmico, matéria textual que conjugaria precisão a um de seus opostos - a abertura ao deslocamento entre sentidos e à afetação sensória. Não reúno evidências para afirmar com precisão científica, mas a minha impressão, ao longo das ofertas, é de que a escolha de uma única ideia a expressar naquela mensagem - como o cuidado, que consta da referência trazida acima - poderia modificar completamente e de modo significante os rumos da ação. Explorarei essa intuição neste texto, adiante.

Os três grupos de WhatsApp a que as pessoas participantes são chamadas a aderir chamaram-se, inicialmente: PROGRAMAS, GIFTS e CHAT. PROGRAMAS é o grupo primordial da ação, por meio do qual são enviados, do dia número um ao dia número 30, textos curtos que, a princípio, identifiquei como programas performativos. No texto do e-mail inicial, explicito às pessoas participantes que os programas que receberão têm o formato de um pequeno texto de ações poéticas que funcionariam como uma sugestão para que fosse realizada ao longo do dia. E continuo: 


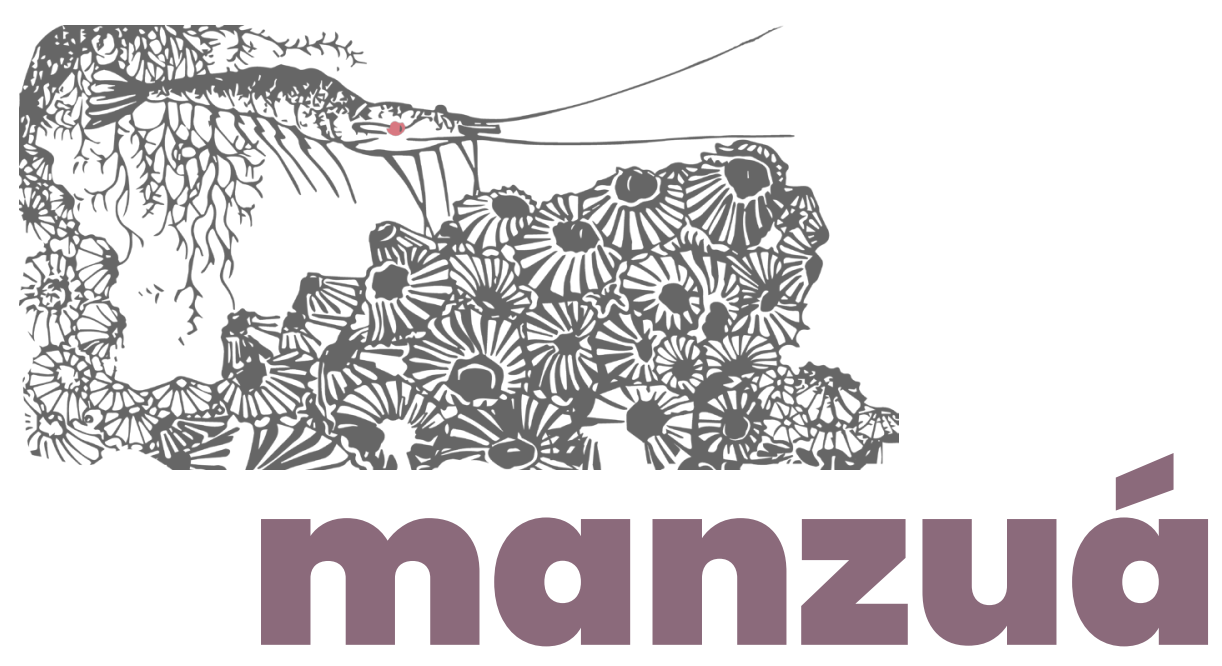

De modo geral, essas ações objetivam tão somente a sua realização. Elas acontecem quando você as realiza, quando percebe $o$ que elas te pedem que perceba - ou sinta, vivencie, experiencie -, quando você reflete sobre o que elas te pedem que reflita. $A$ princípio, não é necessário que você produza nenhum tipo de artefato ou "obra de arte" com essas ações. A obra de arte é a experiência mesma do fazer. (NARDIM, 2020b)

PROGRAMAS é um grupo fechado à interação, no qual só eu, como administradora, posso enviar mensagens. Envio apenas os programas, sempre pela manhã, o mais perto do horário do amanhecer que eu consiga. Os programas são enviados como um arquivo fotográfico, que registra uma escrita caligráfica realizada por mim, com caneta convencional de tinta azul, em folhas de papel almaço pautadas. A partir da segunda oferta, as partir do décimo quinto dia as cores das canetas passaram a variar, o que escolhi fazer para marcar a transição de uma qualidade de proposta a outra, movimento do qual tratarei adiante.

A partir da terceira oferta, deixei de chamar os textos de PROGRAMAS, passando a nomeá-los como TEXTOS-FONTE (e assim passo a chamá-lo neste texto). Assumi essa modificação pois, ao longo do processo das duas primeiras ofertas e por meio do diálogo com as pessoas participantes em nossos chats, questionei-me se o que eu estaria propondo seria de fato entendido como programas performativos se tomássemos com rigor a elaboração dessa noção na bibliografia nacional. Questionei-me, ainda, se era do meu interesse sustentar o vínculo com essa noção, em torno da qual nutro algumas inquietações teóricas - que não exporei neste texto por não estarem suficientemente desenvolvidas. Frente às dúvidas, arrisquei a troca, buscando ainda trazer uma imagem que me soasse mais 


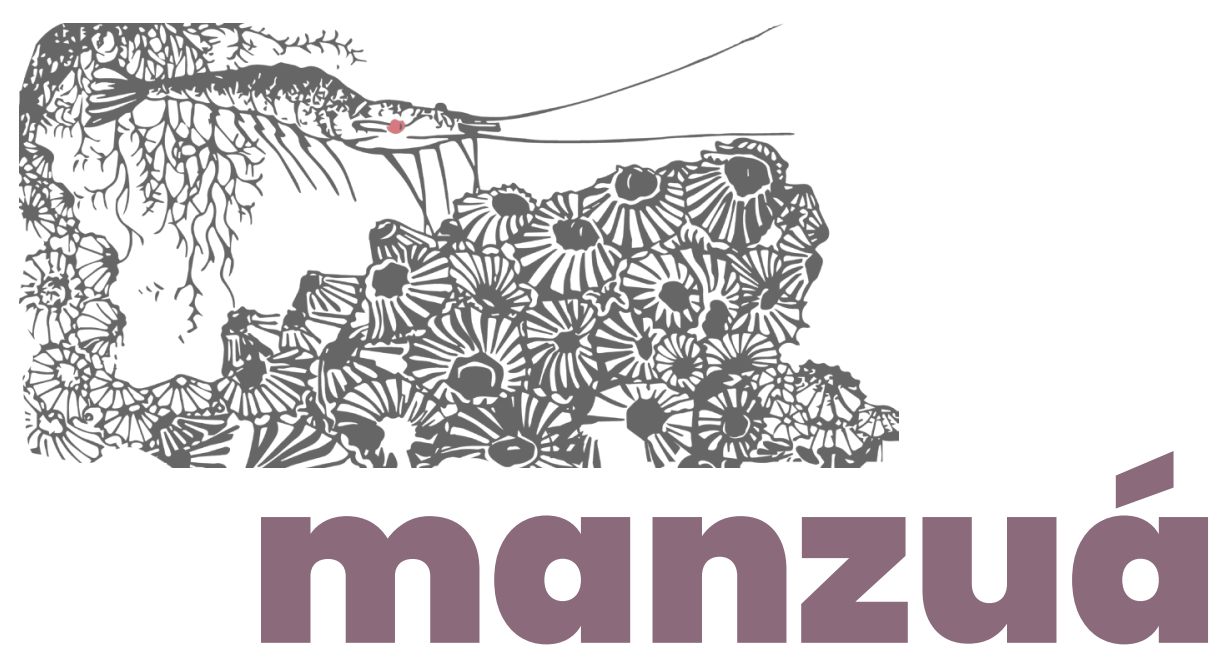

aproximada da multiplicidade de performações e/ou agenciamentos que eu pretendia disparar com aqueles textos - ou que eu pretendia que aqueles textos pudessem vir a disparar.

GIFTS foi assim nomeado para a primeira oferta, tendo passado, a partir da segunda, a chamar-se PARTILHAS - modo pelo qual o nomearei daqui em diante. A ideia era chamá-lo PRESENTES, contudo, o número de caracteres possíveis ao título de um grupo no WhatsApp não contemplava essa palavra na sequência de "Pequenas Perfo -", expressão que introduzia o nome dos três grupos. Em PARTILHAS, as pessoas participantes são convidadas a compartir registros daquilo que realizam a partir dos textos-fonte. Alguns textos-fonte orientam modos de registrar e solicitam que esses registros, em específico, sejam os compartilhados. Contudo, eles são minoria: a maioria das proposições é composta por ações que não têm espectadores - nem mesmo o olhar de dispositivos de registro. Diz o e-mail de início, logo após afirmar que as ações são pensadas para serem experimentadas, e não apresentadas:

Contudo, como temos em vista formar um grupo de apoio e incentivo mútuos para atravessar essa temporada árdua que estamos vivendo, você terá a opção de produzir algo a partir do estímulo da ação e compartilhar, como um presente, com os demais participantes. Pode ser uma fotografia, uma frase, algum som, qualquer coisa que registre ou dê um gostinho da sua experiência com a ação - e que dê pra mandar por whatsapp. (NARDIM, 2020b)

A noção de presente, escolhida para compor a primeira oferta da ação, acabou por disparar uma movimentação inesperada em meados de seu andamento. Narro o ocorrido aqui, não sem antes lembrar às pessoas leitoras de que se trata de uma narrativa 


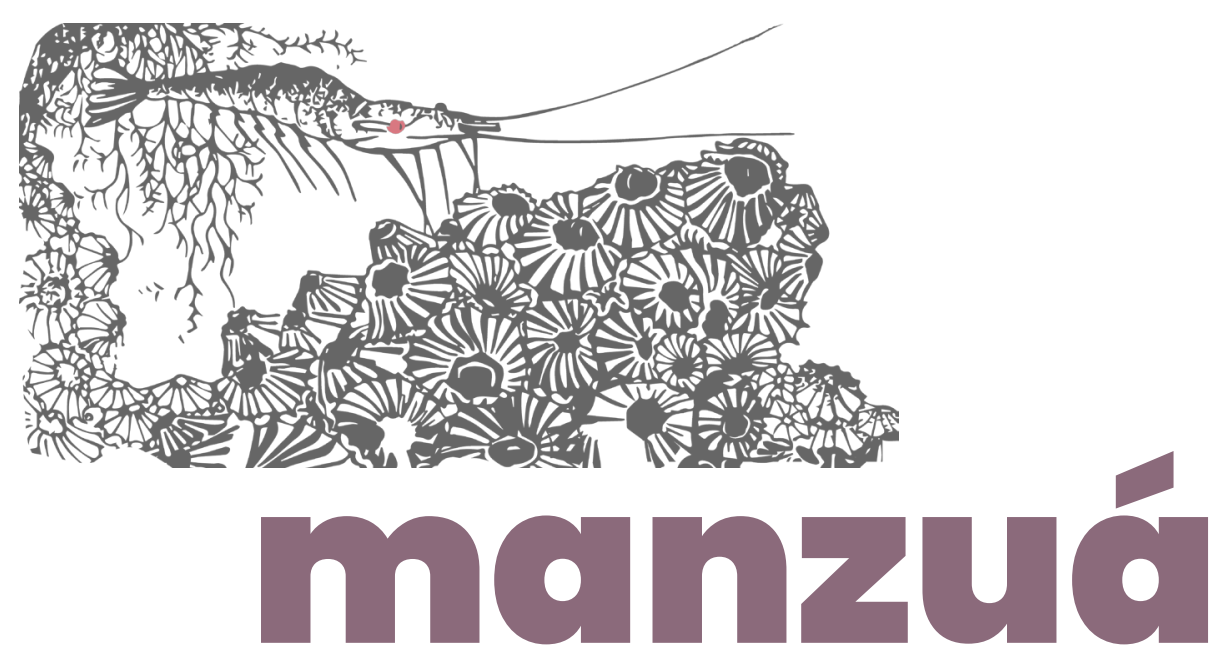

composta a partir da perspectiva da propositora da ação: em certo momento, uma pessoa participante demonstrou sentir-se chateado com a partilha realizada por outra pessoa participante. Em sua mensagem de texto no grupo GIFTS, perguntou: "é isso que você tem para nos oferecer como um presente?". "Você está cuidando de nós com esses envios?" Com isso, iniciou-se um longo debate sobre a noção de presente que ali cada um de nós praticava, que implicou também a noção de cuidado. A pessoa participante questionada sobre seu envio, sentindo-se desrespeitada com a elaboração da mensagem contestatória, retirou-se provisoriamente do grupo. Foi necessário que eu interviesse de um modo mais incisivo do que vinha intervindo até então, conversando individualmente cada um dos dois protagonistas e colocando-os em contato e promovendo uma sessão coletiva de ajuste de entendimentos. Os protagonistas conversaram e se entenderam, e ao que sei, não houve quem deixasse o grupo em decorrência da contenda. A ocasião foi muito pertinente para que eu repensasse a escolha do nome e concluísse que a ideia de partilha era, em relação a presente, simultaneamente mais direcionada, no que se refere à orientação objetiva, e mais aberta, no que se refere à valoração.

Em tempo: o grupo PARTILHAS permanece aberto para interação de todos, durante todo o período da ação.

CHAT é o grupo dedicado ao procedimento que mais se aproxima de um caráter de ensino. Nele, acontecem conversas síncronas, por áudio ou texto - mas majoritariamente por texto, por eleição das pessoas participantes das três ofertas. Em horários previamente agendados da semana - o mesmo horário durante todas as quatro semanas da ação - o grupo, que permanece fechado para interação, é aberto durante uma hora, prazo em que eu atuo como 


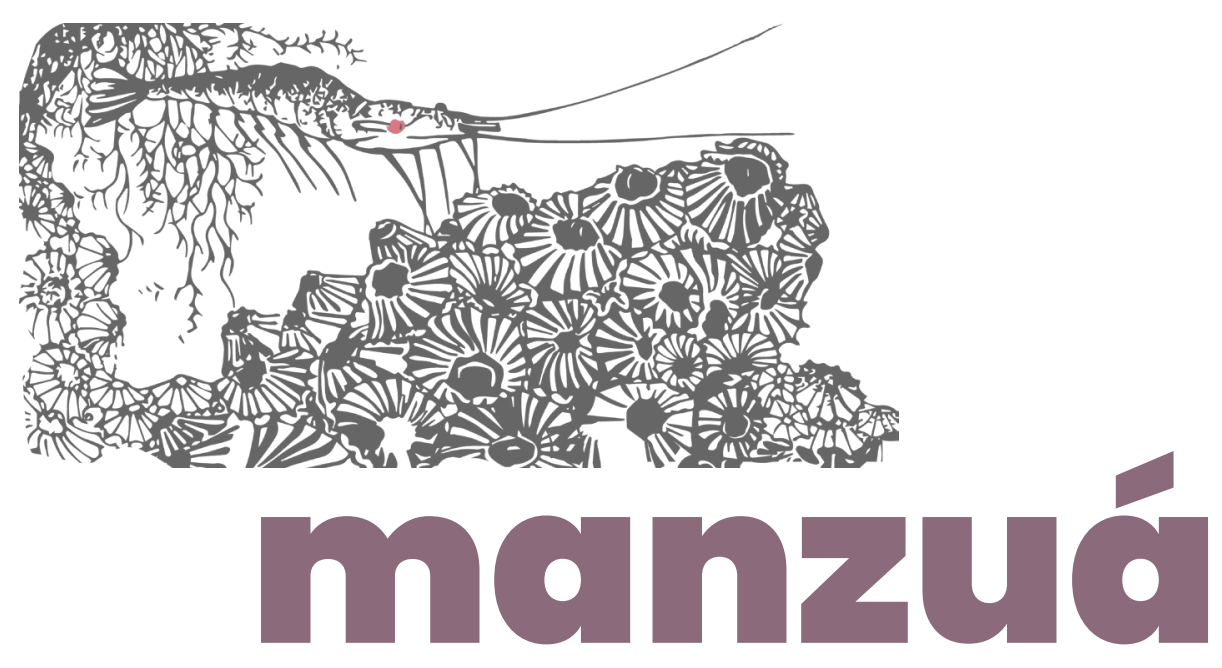

mediadora de uma conversa em torno de temas dos campos da arte da performance, da arte instrucional e de suas adjacências. Durante a primeira oferta, foram realizados dois horários semanais de chats - um no período da tarde e outro no período noturno. Já nas ofertas dois e três, que contavam com maior número de participantes, foram realizados três horários semanas - um pela manhã, outro à tarde, e um à noite.

A abrangência ou recorte temáticos da conversa, bem como a intensidade da mediação, variaram muito a cada chat, em função do número de participantes, de suas disposições, desejos e saberes, e também de acordo com a característica dos grupos. Esta última variante, inclusive, é digna de nota tanto nos chats quanto nas partilhas, em que a quantidade de participações diárias me proporcionou uma experiência extremamente diversa de uma oferta para outra.

Ainda no e-mail de início, informo às pessoas participantes que a adesão a PARTILHAS e CHAT é opcional. Ainda que a experiência tenha sido projetada para abarcar as interações que acontecem por entre esses três grupos, compreendi que a opção por apenas receber OS TEXTOS-FONTE e não partilhar registros, ou por recebê-los e interagir no CHAT, mas não no PARTILHAS - e vice-versa, também era legítima e não traria nenhum constrangimento, desde que todos estivessem informados da possibilidade desde o início. Assim, a elaboração de todos os TEXTOS-FONTE, bem como a condução dos chats, teve de sempre levar em conta as múltiplas possibilidades de interação - o que demandou de mim um especial desprendimento com relação ao acompanhamento das reverberações do processo, vivência que pretendo analisar em ocasião oportuna. 


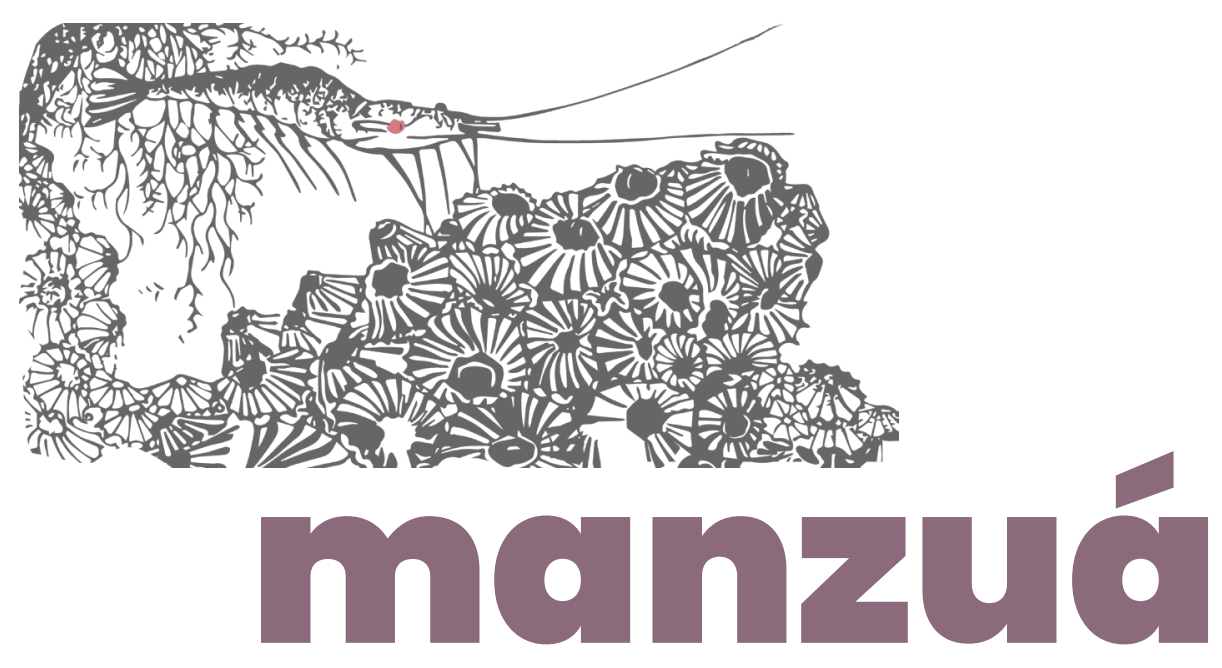

\section{TEMATIZANDO}

Olhar para estrutura da ação é imprescindível, já que se trata concretizar uma forma-conteúdo, mas não alcançamos toda a imagem de Pequenas Performances se não digo daquilo que os textos-fonte tematizam. Entra em jogo aqui, para além de quando impôs a realização da ação pela mediação do whatsapp, a prática do isolamento social preventivo à COVID-19. Considerando que, idealmente e contextualmente, o público da ação estaria vivendo a maior parte de seu tempo, senãoem absoluto, dentro de sua residência ou de um espaço que fizesse as vezes de, as Pequenas Performances são aquelas que serão realizadas na casa, para a casa e com a casa. $E$, mais que isso, não serão ações agigantadas, impressionantes, figurativas, representativas, ousadas, grandiloquentes - mas serão, sim, pequenas - tanto em escala quanto em pretensões expressivas. Serão ações que talvez sejam performance, talvez não - e tudo bem. Esbarrarão em reverberações terapêuticas, talvez inspirem esperanças de uma atitude orientada a outros mundos possiveis. Consistirão numa pequena pedagogia do parar e reparar, chamando sempre para a conversa o lugar que a pessoa participante constrói como sua casa.

Capturar com os olhos a cor do céu e procurar, na casa, esses azuis. Comparar cores do corpo com cores da casa, compor com elas, unificá-las. Elaborar um altar pela combinação de objetos que remetem a seres do exterior. Tocar para as paredes música com elementos da casa. Conscientizar-se de fluxos de líquidos no corpo em contraste aos fluxos de líquido na casa. Permitir a um canto jamais habitado que te informe as maneiras de habitá-lo. Modificar o lugar de todos os móveis de um cômodo, só por hoje. Limpar a casa muito vagarosamente, lavar assim a louça. 


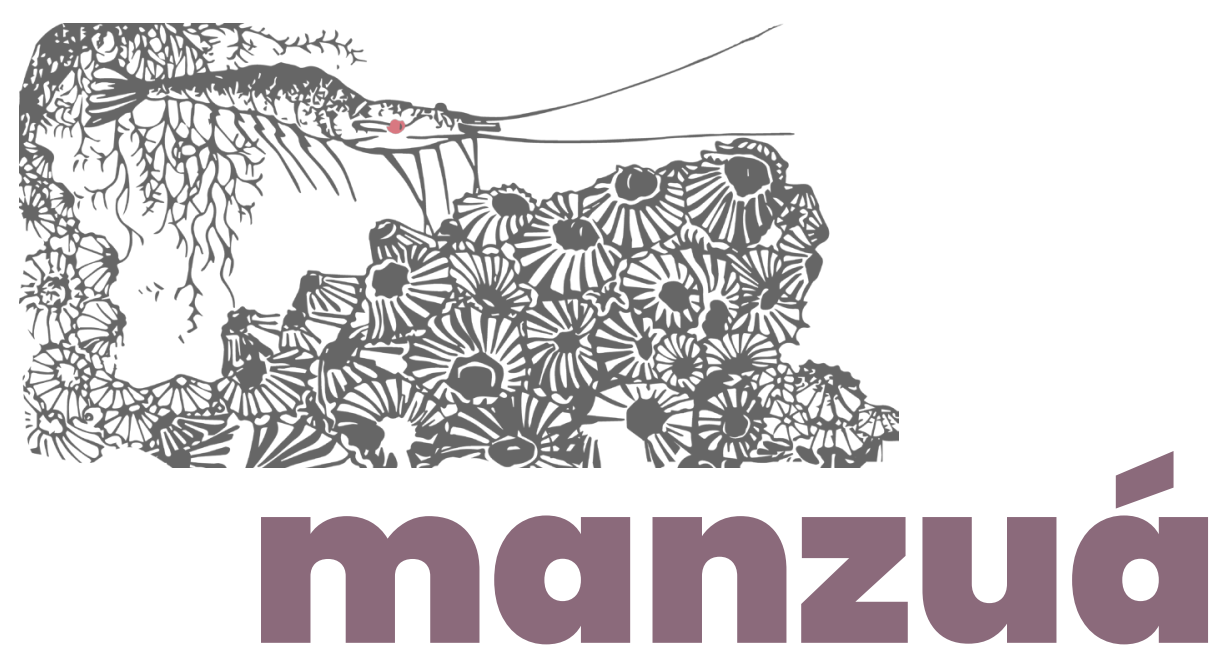

Propostas como essas foram apresentadas ao longo de 30 dias pelos textos-fonte da primeira oferta. Já na segunda e na terceira, incorporamos - graças a uma co-criação com meu parceiro de jornada Flávio Rabelo - orientações que se voltaram mais à segunda parcela do título da ação - à "arte do bem para mundos possíveis": encontrar na casa um objeto de força que assuma a função de amuleto na construção de outros mundos possiveis (melhores); gritar contra objetos indesejáveis o seu grito de guerra rumo a outros mundos possiveis (melhores); criar com objetos as ferramentas poéticas necessárias aos usos que conduzem a outros mundos possiveis (melhores); realizar, quiçá ironicamente, uma manifestação ativista em seu sofá.

A casa - vista, simultaneamente, como material e como agente. A ação cotidiana revista, reproposta, para que se veja, sinta e compreenda de modos outros a casa. A qualidade de arte colocada no deslocamento da percepção, na automanipulação da atenção, no manejo do atentar-se. Pequenas Performances como uma coreografia de sentidos - sendo, portanto, dança. Pequenas Performances como a confrontação do corpo com a matéria, mesmo quando apenas confrontação do olhar com cor e luz - sendo, portanto, artes visuais. Pequenas Performances como notar, capturar emitir sonoridades, ouvir a música que emana dos ralos, engendrar arranjos entre o que se ouve e o que se diz - sendo, portanto, música. Pequenas Performances como representar a si mesmo - sendo, portanto, teatro.

\section{POUSANDO, PAUSANDO}

Pequenas Performances como um exercício de escrever, criando; um exercício de encontrar, criando, também - comunhando; 


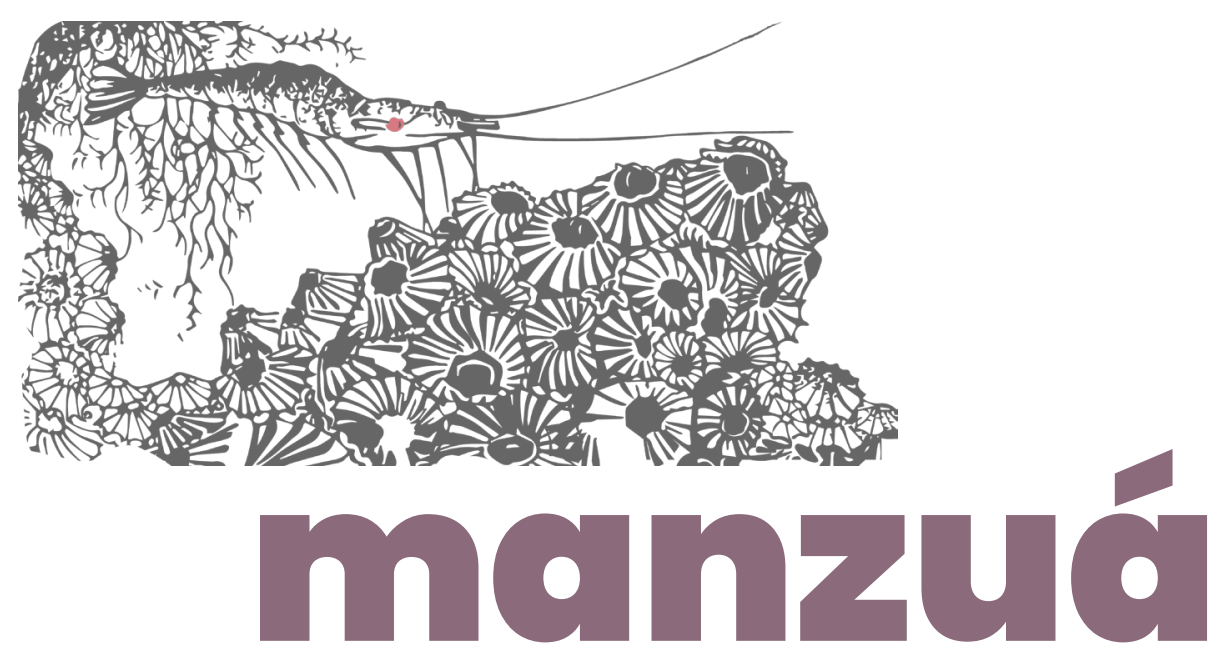

de inventar um meio para alcançar, com a arte da performance ou com aquilo a que sou conduzida pelo meu contato com práticas em arte da performance - pessoas distantes e até então inacessiveis. Pequenas Performances de uma docente que elabora estratégias que congregam rigidez e flexibilidade com justeza - bolando jogos para ver emergirem diferenças que não sabemos a que vêm. Pequenas Performances de uma pesquisadora, tanto em arte quanto em pensamento-acadêmico, criando dados ao invés de coletá-los, criando traços que se inscrevem em sua carne-pesquisa-docênciacriação.

Até aqui, omiti das pessoas leitoras uma informação: todos os textos-fonte são escritos por mim, imediatamente antes de enviá-los, a partir de um texto-fonte disparador ou gerador: 


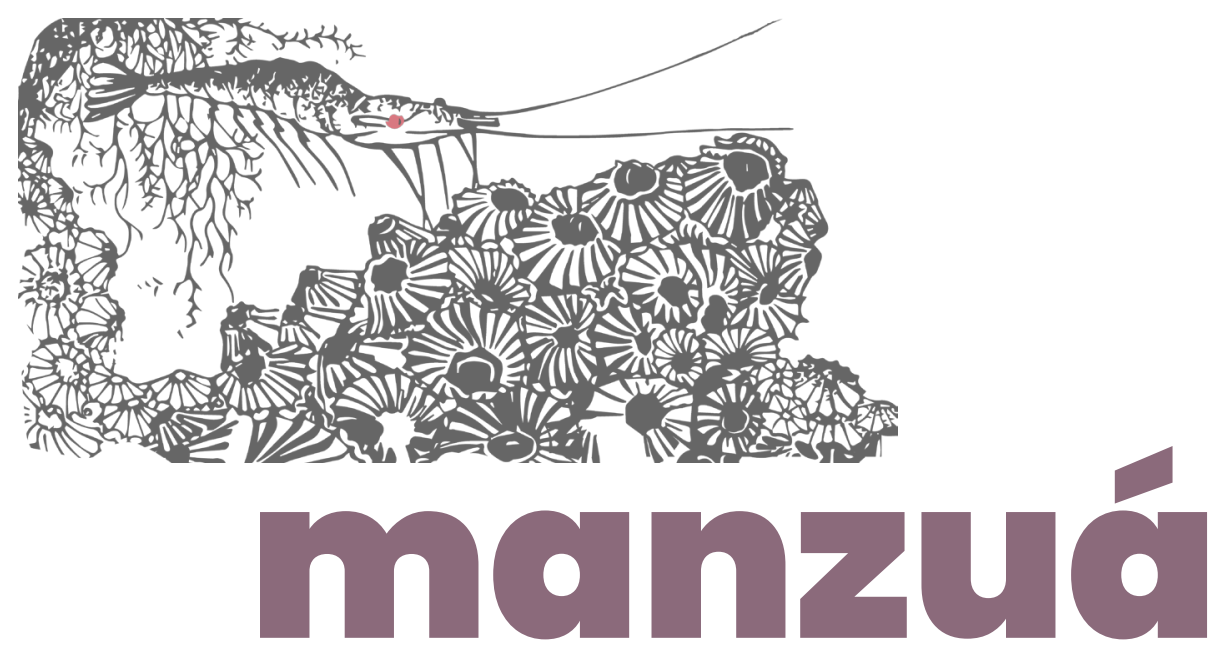

Durante 30 dias, acordar às 06h. Olhar o céu. Estar na casa. Alinhar pés-cabeça. Escrever um texto-fonte. Fotografá-lo. Enviá-lo.

Foram ao todo, até hoje, 90 dias de programa disparador. Em alguns desses dias, na segunda e na terceira ofertas, eu travei e acabei optando por copiar ou reescrever programas das ofertas anteriores. Mas, para além das quantidades, o que busco destacar aqui é a presença da prática de escrita nos meus dias, assim como a presença reiterada dos textos-fontes que aportavam pela manhã nos dispositivos das pessoas participantes. 


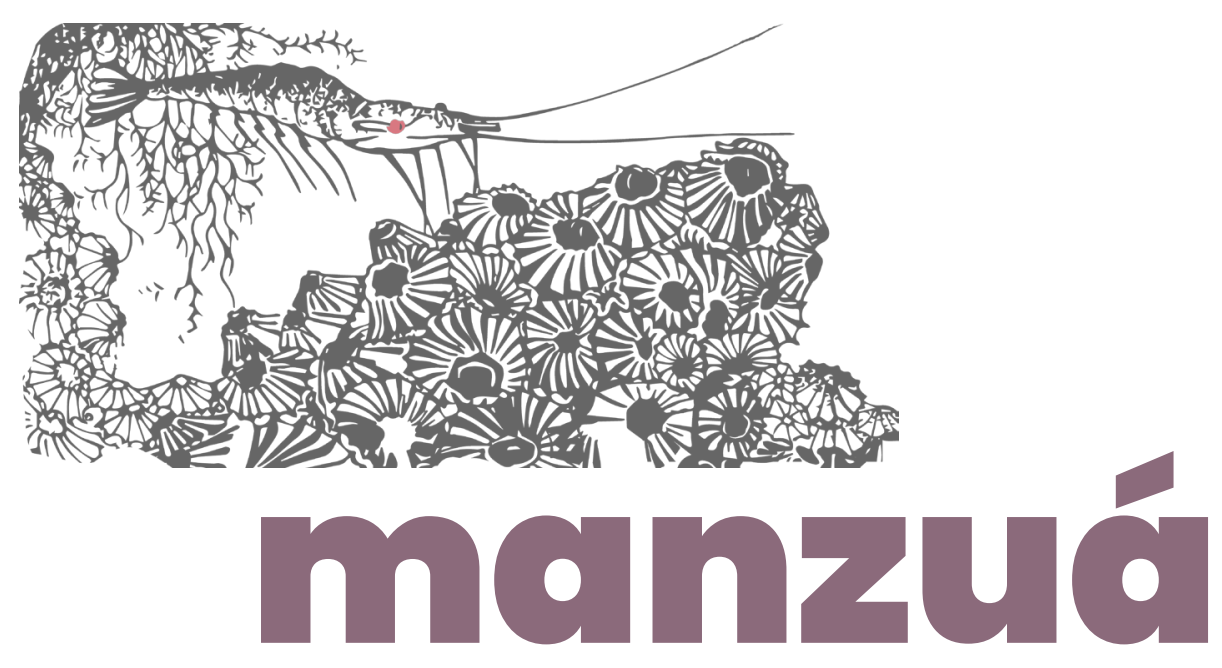

Uma ação que, mais que um híbrido de arte, educação e pesquisa, propõe-se a ser arte e educação e pesquisa e prática. Prática cotidiana, insistência, que se encontra no corpo com os fazeres outros, os fazeres todos. Agregando a publicização possível de uma instância privada - dar a ver o que, da experiência da casa pode-se ver - e o exercício íntimo de orientações que vêm de fora, mais ou menos direcionadas, essas práticas apresentam-se como consolidações carnais, ainda que provisórias, de pensamentos, reflexões, metodologias.

Como uma proposição em pesquisa-docência-criação, Pequenas Performances apresenta-se como um estar de corpo presente a assistir, construindo, a variação - insistência em manter as mãos no trabalho de cavar a abertura permanente à irrupção - jogo entre elementos que abrem e fecham, vêm e vão. Isso pode ser arte, é fácil de ver. Isso pode ser pesquisa - quando eu afirmo que pode, vocês veem. $E$ isso pode também ser docência - o que já parece, então, difícil de visualizar, eu suponho (tudo que posso é supor).

Como uma derivação esforçada de pesquisa-docênciacriação em chave "E", Pequenas Performances busca materializar, sem esquecer-se das dimensões afetivas e agenciais da matéria, um contínuo que seguirá sendo praticado até que encontre um acidente que o faça cessar - derivando, enquanto eu sustentar-me em AND, para novas composições em associação daquilo que constitui as contingências que me cercam e que comigo emergem - mulher, 36 anos, paulista tocantinada, professora de teatro, artista e gestora em arte da performance e... e... e... e... 


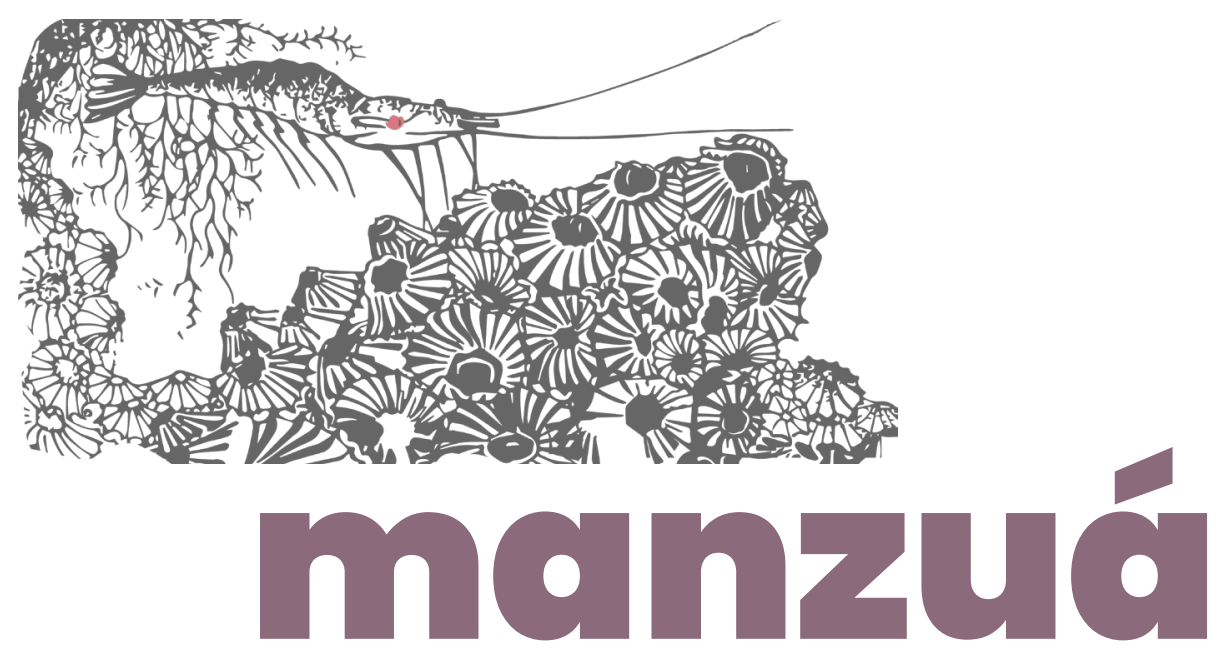

\section{REFERÊNCIAS}

EUGENIO, Fernanda. Caixa-livro AND. Rio de Janeiro: fadainflada, 2019.

Thaíse NARDIM. Palmas: EdUFT, 2020a.

NARDIM, Thaíse. COMEÇANDO - Pequenas Performances para isolados. Mensagem enviado por thaise.nardim@gmail.com em 18 maio 2020b. 